\title{
Synthesis, Cytotoxic and Antihyperlipidemic Activities of Some New coumarinyl 4-Thiazolidinone Derivatives
}

\author{
Katte Ishwar Bhat, Abhishek Kumar*, Pankaj Kumar \\ Department of Pharmaceutical Chemistry, NGSM Institute of Pharmaceutical Sciences, NITTE (Deemed to be University), Paneer, \\ Deralakatte, Mangaluru, Karnataka, INDIA.
}

\begin{abstract}
Background: Despite tremendous advancements both in early diagnosis and approaches to treatment, cancer still remains an unconquered problem. The development of new chemotherapeutic agents for the treatment of cancer with fewer side effects is an important goal for medicinal chemists. Hyperlipidemia is a worth-mentioning risk factor in quickly expanding cardiovascular diseases, including myocardial infarction and, furthermore, in stroke. Hence, there is a need to develop new cytotoxic and antihyperlipidemic drugs. Materials and Methods: In the present study, a series of new substituted 2-(4-hydroxy-2-oxo-2H-chromen-3-yl)-2-methyl-3-phenylthiazolidin-4-one (TKA1-TKA13) were synthesized by reacting various 4-hydroxy-3-(1-(phenylimino) ethyl)-2H-chromen-2-one with thioglycollic acid. The intermediate 4-hydroxy-3-(1(phenylimino) ethyl)-2H-chromen-2-one (SKA1-SKA13) were synthesized by reacting 4-hydroxyl coumarin with various substituted anilines in alcohol medium. All the newly synthesized compounds were assigned on the basis of $\mathrm{IR},{ }^{1} \mathrm{H}$ NMR and mass spectral data. Results: The newly synthesized compounds were evaluated for in-vitro cytotoxic activity using Methyl Thiazolyl Tetrazolium (MTT) assay and in-vitro antihyperlipidemic activity by HMG-CoA reductase assay. Compound TKA12 possess potent cytotoxic activity on lung adenocarcinoma cells in a concentration dependent manner compared to the standard cisplatin. Most of the compounds showed potent antihyperlipidemic activity comparable with that of the standard pravastatin. Conclusion: The in-vitro results suggest that most of the compounds may be a promising antihyperlipidemic molecules and compound TKA12 showed potent cytotoxic activity which can be further determined by in vivo studies.
\end{abstract}

Key words: Coumarins, Schiff bases, 4-Thiazolidinones, Cytotoxic activity, Antihyperlipidemic activity.

\section{INTRODUCTION}

Cytotoxic drugs and chemotherapy still remain the most important area of research. Enhancement and approaches to anticancer drugs seemed to be a major area of investigation, despite the continuous progress of anticancer agents, overall control of cancer is still a dream. ${ }^{1}$ Great effort was exerted to develop new anticancer agents with high toxicity toward cancer cells and with a minimal toxicity against normal cells. Coumarin is a fragrant organic chemical compound in the benzopyrone chemical class, which is a colourless crystalline substance in its standard state. Coumarins are the best known aromatic lactones. Coumarin derivatives constitute an important class of compounds with a wide range of biological activities. In particular, they are important as photo chemotherapeutic agents that are used to treat a variety of skin diseases. They have been also found to exhibit antitumour, ${ }^{2}$ antioxidant, ${ }^{3}$ anti-inflammatory, ${ }^{4}$ antimicrobial $^{5}$ and antidiabetic activities.
Submission Date: 15-01-2021; Revision Date: 16-02-2021; Accepted Date: 09-08-2021

DOI: 10.5530/ijper.55.3s.188 Correspondence: Dr. Abhishek Kumar (M.Pharm, Ph.D), Assistant Professor, Department of Pharmaceutical Chemistry, NGSM Institute of Pharmaceutical Sciences, NITTE (Deemed to be University) Paneer, Deralakatte, Mangaluru- 575018,

Karnataka, INDIA. Phone: +91 8746063684, Email-abhi12bunty@nitte. edu.in

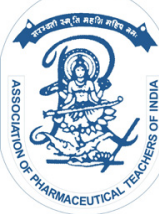

www.ijper.org 
4-Thiazolidinones are derivative of thiazolidinone with carbonyl group at the $4^{\text {th }}$ position and formed by the attack of sulphur nucleophile on imine carbon followed by intramolecular cyclisation with elimination of water. The chemistry of thiazolidin-4-one ring systems is of considerable interest as it is a core structure in various synthetic pharmaceuticals displaying a broad spectrum of biological activities such as antidiabetic, anticonvulsant, anticancer ${ }^{6}$ antihyperlipidemic, ${ }^{7}$ antimicrobial, antitubercular and antioxidant activities. Obesity is an emerging issue in most OECD countries. Statins are cholesterol-lowering drugs that are widely used to inhibit 3-hydroxy-3-methyl-glutaryl (HMG)CoA reductase activity involved in cholesterol production in liver. However, potential adverse side effects have been identified in muscle and liver enzymes, such as the cytochrome P450 3A4 system. Therefore, it is worthwhile to investigate alternatives to statins, even if the side effects attributed to statins are rare.

By considering the above facts and their increasing importance in pharmaceutical and biological field, it was contemplated to synthesize some new heterocyclic moieties incorporating the two active pharmacophore in a single molecular frame work and to evaluate their biological activities. Hence an attempt was made towards the incorporation of 4-thiazolidinone with coumarin moiety to probe how this combination could influence the antihyperlipidemic and cytotoxic activity.

\section{MATERIALS AND METHODS}

All the chemicals were of analytical grade: 4-hydroxy coumarin, pyridine, piperidine, substituted aromatic amine, acetyl chloride, ethanol, thioglycollic acid and dioxane.

Melting points were determined by open capillary method and are uncorrected. Purity of the intermediates and final compounds were monitored by thin layer chromatography (TLC) using silica gel G plates. The spots were visualized under UV light. $n$-hexane: Ethylacetate (7:3) was used as solvent for running the TLC of these compounds as given in Table 1. All IR spectra were recorded in Alpha Bruker using ATR method. ${ }^{1} \mathrm{H}$ NMR spectra were recorded on Bruker spectrophotometer (400 MHz) in DMSO-d ${ }_{6}$ solvent using tetra methyl silane (TMS) as an internal standard. Mass spectra was recorded by ESI method.

\section{3-Acetyl-4-hydroxy coumarin ${ }^{8}$}

4-hydroxy coumarin $(0.01 \mathrm{~mol})$ was dissolved in $30 \mathrm{ml}$ of dry pyridine and few drops of piperidine was added and the contents were cooled to $0-4^{\circ} \mathrm{C}$. Acetyl chloride $(0.01 \mathrm{~mol})$ was added to the reaction mixture and shaken for 48 hrs. The reaction mixture was cooled and poured into crushed ice and acidified with conc. $\mathrm{HCl}(\mathrm{pH}$ 1-2). The precipitated compound was filtered, washed with water and recrystallized from ethanol.

\section{4-hydroxy-3-(1-(phenylimino)ethyl)-2 $\mathrm{H}$-chromen- 2-one ${ }^{9}$ (SKA1-SKA13)}

Equimolar solutions of 3-acetyl-4-hydroxy coumarin $(0.01 \mathrm{~mol})$ and substituted aromatic amine $(0.01 \mathrm{~mol})$ were mixed in $50 \mathrm{ml}$ ethanol and the reaction mixture was refluxed for $4 \mathrm{hrs}$. After cooling, the reaction mixture was poured into crushed ice. The product was filtered, washed with water and recrystallized from ethanol.

\begin{tabular}{|c|c|c|c|c|c|c|}
\hline \multicolumn{6}{|c|}{ Table 1: Physicochemical data of Coumarin Incorporated 4-Thiazolidinone Derivatives (TKA1-TKA13). } \\
\hline Compound Code & $\mathbf{R}$ & Mol. Formula & Mol. wt & Melting point ${ }^{\circ} \mathbf{C}$ & $\mathbf{R}_{f}$ value & \% Yield \\
\hline TKA1 & $\mathrm{H}$ & $\mathrm{C}_{19} \mathrm{H}_{15} \mathrm{NO}_{4} \mathrm{~S}$ & 353 & $80-82$ & 0.62 & 69 \\
\hline TKA2 & $2-\mathrm{Cl}$ & $\mathrm{C}_{19} \mathrm{H}_{14} \mathrm{CINO}_{4} \mathrm{~S}$ & 387 & $104-106$ & 0.72 & 71 \\
\hline TKA3 & $4-\mathrm{Cl}$ & $\mathrm{C}_{19} \mathrm{H}_{14} \mathrm{CINO}_{4} \mathrm{~S}$ & 387 & $118-120$ & 0.52 & 70 \\
\hline TKA4 & $2-\mathrm{NO}_{2}$ & $\mathrm{C}_{19} \mathrm{H}_{14} \mathrm{~N}_{2} \mathrm{O}_{6} \mathrm{~S}$ & 398 & $152-154$ & 0.68 & 65 \\
\hline TKA5 & $4-\mathrm{NO}_{2}$ & $\mathrm{C}_{19} \mathrm{H}_{14} \mathrm{~N}_{2} \mathrm{O}_{6} \mathrm{~S}$ & 398 & $108-110$ & 0.56 & 80 \\
\hline TKA6 & $4-\mathrm{Br}$ & $\mathrm{C}_{19} \mathrm{H}_{14} \mathrm{BrNO}_{4} \mathrm{~S}$ & 432 & $198-200$ & 0.60 & 66 \\
\hline TKA7 & $4-\mathrm{F}$ & $\mathrm{C}_{19} \mathrm{H}_{14} \mathrm{FNO}_{4} \mathrm{~S}$ & 311 & $148-150$ & 0.74 & 60 \\
\hline TKA8 & $2-\mathrm{CH}_{3}$ & $\mathrm{C}_{20} \mathrm{H}_{17} \mathrm{NO}_{4} \mathrm{~S}$ & 367 & $184-186$ & 0.68 & 62 \\
\hline TKA9 & $3-\mathrm{OCH}_{3}$ & $\mathrm{C}_{20} \mathrm{H}_{17} \mathrm{NO}_{5} \mathrm{~S}$ & 383 & $208-210$ & 0.58 & 68 \\
\hline TKA10 & $2,4-\mathrm{NO}_{2}$ & $\mathrm{C}_{19} \mathrm{H}_{13} \mathrm{~N}_{3} \mathrm{O}_{8} \mathrm{~S}$ & 443 & $158-160$ & 0.70 & 78 \\
\hline TKA11 & $2-\mathrm{CH}_{3} 4-\mathrm{NO}_{2}$ & $\mathrm{C}_{20} \mathrm{H}_{16} \mathrm{~N}_{2} \mathrm{O}_{6} \mathrm{~S}$ & 412 & $174-176$ & 0.64 & 81 \\
\hline TKA12 & $3-\mathrm{Cl} 4-\mathrm{F}$ & $\mathrm{C}_{19} \mathrm{H}_{13} \mathrm{ClFNO}_{4} \mathrm{~S}$ & 405 & $180-182$ & 0.76 & 79 \\
\hline TKA13 & $3,4-\mathrm{Cl}$ & $\mathrm{C}_{19} \mathrm{H}_{13} \mathrm{Cl}_{2} \mathrm{NO}_{4} \mathrm{~S}$ & 422 & $184-186$ & 0.72 & 82 \\
\hline
\end{tabular}


Substituted 2-(4-hydroxy-2-oxo-2H-chromen-3-yl)2-methyl-3-phenylthiazolidin-4-one ${ }^{10}$ (TKA1-TKA13)

\section{General Procedure}

A mixture of Schiff bases $(0.001 \mathrm{~mol})$ and thioglycollic acid $(0.002 \mathrm{~mol})$ were mixed in $10 \mathrm{ml}$ dioxane and refluxed for 9-10 hrs. The reaction mixture was cooled and poured into crushed ice. The precipitated compound was filtered and recrystallized from ethanol as given in Figure 1.

\section{Evaluation of Cytotoxic Activity}

\section{MATERIALS AND METHODS}

Cytotoxicity of the test compounds was assessed using Methyl Thiazolyl Tetrazolium MTT assay. ${ }^{11}$

\section{Cells and culture conditions}

Lung adenocarcinoma (A549) cells were procured from National Centre for Cell Sciences (NCCS), Pune. They were cultured in Dulbecco's Modified Eagle's Medium (DMEM) supplemented with 10\% FBS and 1\% antibiotic-antimycotic solution. Cells were maintained at $37^{\circ} \mathrm{C}$ and $5 \% \mathrm{CO}_{2}$ in a humidified atmosphere and were used for the experiments at least after three consecutive passages.

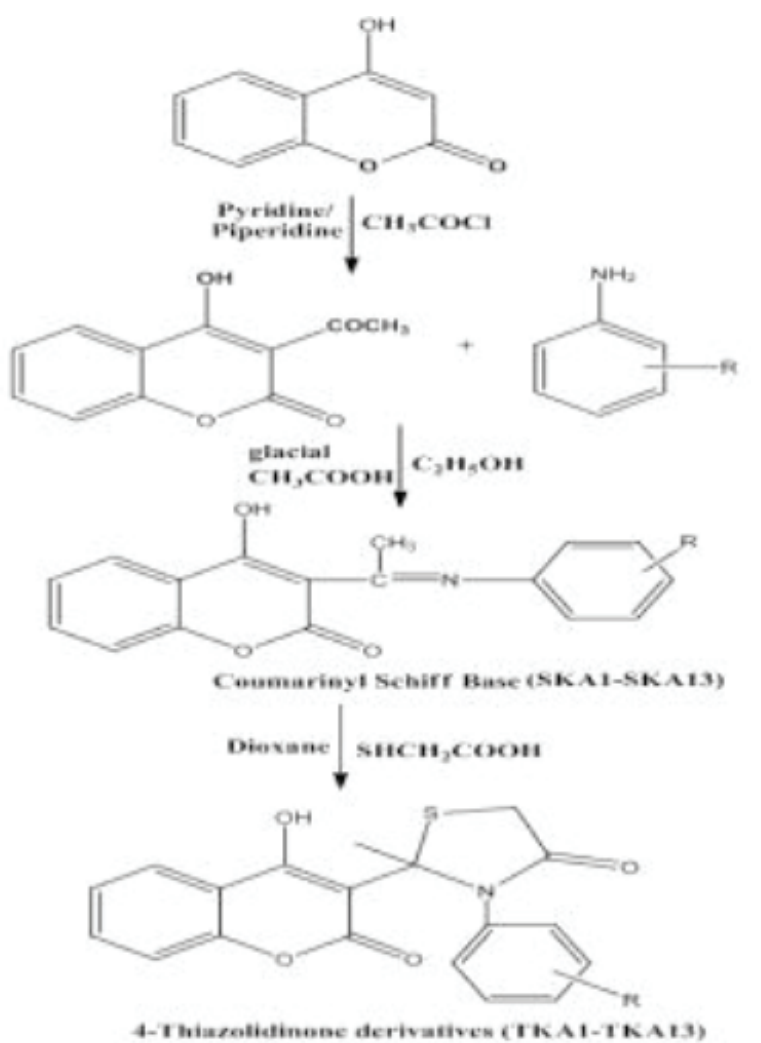

Figure 1: Scheme for synthesis of 4-thiazolidinone derivatives.

\section{Assessment of cytotoxicity}

Cells were seeded onto 96 well microtitre plates at a seeding density of 5000 cells/well. After adherence, they were treated with different concentrations of the test compounds, viz., $6.25,12.5,25,50$ and $100 \mu \mathrm{g} / \mathrm{ml}$. $48 \mathrm{hrs}$ post-incubation with test compounds, MTT reagent was added to the wells and incubated at $37^{\circ} \mathrm{C}$ for 4 hrs. Formazan crystals formed were solubilized using DMSO and absorbance was recorded at $570 \mathrm{~nm}$ using multimode microplate reader (FluoSTAR Omega, BMG Labtech). Percentage cytotoxicity of the test compounds was calculated with respect to untreated cell control.

\section{Evaluation of Antihyperlipidemic Activity}

HMG CoA reductase are the essential enzyme required for the biosynthesis of cholesterol, where acetyl CoA is the precursor. HMG CoA reductase is important in the conversion of HMG CoA to mevalonic acid in the initial steps of cholesterol biosynthesis. Since synthesis of cholesterol can be blocked by antihypercholesterolemic by inhibiting this enzyme, they gained importance in the therapy of hyperlipidemia. ${ }^{12}$

In the present study, in vitro antihyperlipidemic activity was performed by HMG CoA Reductase assay. This in vitro assay is generally used to assess the antihyperlipidemic potency of a chemical derivative. The known statins display their antihyperlipidemic potency by inhibiting this HMG CoA reductase enzyme. In liver, LDL receptors are expressed because of the inhibition of this enzyme which results in the lower plasma concentration of cholesterol. This is an NADPH-dependent reaction.

HMG-CoA Reductase Activity Assay Kit (Colorimetric) taken from sigma Aldrich (catalog number CS1090) was used to screen the antihyperlipidemic activity of synthesized compounds. This kit has, HMG CoA reductase, an inhibitor pravastatin and NADPH and HMG CoA reductase assay buffer. Assay kit evaluates the consumption of NADPH, which can be determined by the decrease in absorbance at $\mathrm{OD}=340 \mathrm{~nm}$. So in this assay activity of purified enzyme in addition to testing of antihypercholesterolemic (synthesized compounds). ${ }^{13}$

$$
\% \text { Inhibition }=\frac{[\Delta \text { absorbance test }]}{[\Delta \text { absorbance control }]} \times 100
$$

\section{Assay Procedure}

Equilibrated all materials and prepared reagents to room temperature prior to use. 
1. Assay was performed in 96 well plate.

2. Different concentration of test compounds were prepared with suitable solvents and sufficient quantity of test samples $(5 \mu \mathrm{l})$ was added into wells of the titre plate.

3. $5 \mu \mathrm{l}$ Inhibitor Pravastatin is added to another well which serves as standard.

4. Sufficient amount of Assay buffer from the kit was added to each buffer.

5. Reconstituted NADPH was added to all the sample.

6. Substrate HMG CoA and enzyme HMG CoA was added both test and standard samples.

7. All the reagents without test/standard drug was served as control.

8. Mixed the sample thoroughly.

9. Absorbance was measured immediately under kinetic program at $\mathrm{OD}=340 \mathrm{~nm}$.

\section{RESULTS AND DISCUSSION}

\section{Cytotoxic activity}

Compound TKA12 possess potent cytotoxic activity on lung adenocarcinoma cells in a concentration dependent manner as given in Table 2. Highest cytotoxicity with these compounds was observed at 50 and $100 \mu \mathrm{g} / \mathrm{ml}$ concentrations. Compounds that show $>50 \%$ toxicity at concentrations less than $50 \mu \mathrm{g} / \mathrm{ml}$ concentration on cancer cells, are considered as potential cytotoxic agents. The reference standard cisplatin showed 73.2\% cytotoxicity under the similar treatment conditions at $25 \mu \mathrm{g} / \mathrm{ml}$ concentration. Compounds TKA2, TKA11 and TKA12 showed IC50 comparable to the standard cisplatin. The presence of electron withdrawing group like chloro, nitro and fluoro resulted in increased cytotoxic activity.

Compound TKA10 possess potent cytotoxic activity on human breast cancer cell line MCF-7 compared to the standard cisplatin as given in Table 3 and Figure 2. The presence of electron withdrawing group like nitro resulted in increased cytotoxic activity.

Compound TKA11 possess potent cytotoxic activity on lung adenocarcinoma cells NCIH-460 compared to the standard cisplatin as given in Table 4 and Figure 3. The presence of electron withdrawing group like nitro resulted in increased cytotoxic activity.

\section{Antihyperlipidemic activity}

All the synthesized compounds were screened for in vitro antihyperlipidemic by HMG CoA reductase assay to determine the antihyperlipidemic potency.

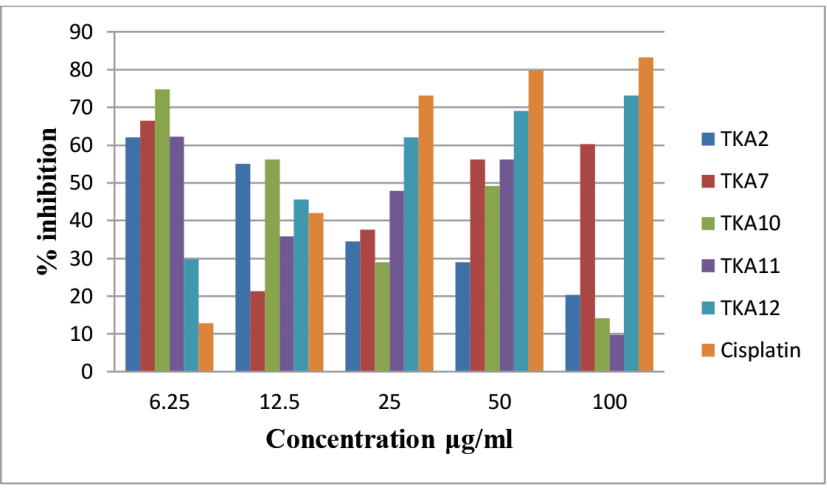

Figure 1: Cytotoxicity of the tested compounds on A549 assessed using MTT assay.

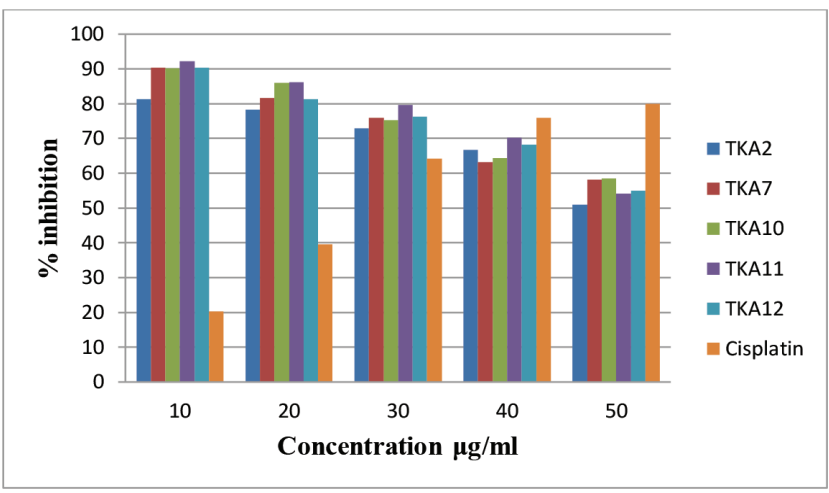

Figure 2: Cytotoxicity of the tested compounds on MCF-7 assessed using MTT assay.

\begin{tabular}{|c|c|c|c|c|c|c|}
\hline \multicolumn{7}{|c|}{ Table 2: Cytotoxicity of the tested compounds on A549 assessed using MTT assay. } \\
\hline \multirow{2}{*}{ Conc $(\boldsymbol{\mu g} / \mathrm{ml})$} & \multicolumn{7}{|c|}{ Cytotoxicity (Mean \pm SD) } \\
\cline { 2 - 7 } & TKA2 & TKA7 & TKA10 & TKA11 & TKA12 & Cisplatin \\
\hline $\mathbf{6 . 2 5}$ & $9.54 \pm 0.16$ & $11.04 \pm 0.13$ & $12.51 \pm 1.27$ & $9.68 \pm 0.28$ & $29.85 \pm 0.70$ & $12.83 \pm 0.25$ \\
\hline $\mathbf{1 2 . 5}$ & $12.38 \pm 0.95$ & $21.24 \pm 0.54$ & $14.20 \pm 2.00$ & $35.75 \pm 0.31$ & $45.66 \pm 0.74$ & $41.94 \pm 0.30$ \\
\hline $\mathbf{2 5}$ & $32.82 \pm 1.84$ & $37.55 \pm 1.17$ & $29.01 \pm 0.69$ & $47.80 \pm 0.42$ & $62 \pm 1.01$ & $73.2 \pm 0.39$ \\
\hline $\mathbf{5 0}$ & $33.86 \pm 0.21$ & $56.25 \pm 0.11$ & $49.21 \pm 1.13$ & $56.23 \pm 0.35$ & $69.06 \pm 2.91$ & $79.88 \pm 0.37$ \\
\hline $\mathbf{1 0 0}$ & $39.86 \pm 0.19$ & $66.38 \pm 1.10$ & $74.81 \pm 1.17$ & $62.18 \pm 0.75$ & $73.16 \pm 2.29$ & $83.21 \pm 0.45$ \\
\hline IC $_{50}$ & 8.25 & 41.26 & 21.80 & 13.85 & 17.05 & 18.75 \\
\hline
\end{tabular}




\begin{tabular}{|c|c|c|c|c|c|c|}
\hline \multirow[t]{2}{*}{ Conc $(\mu \mathrm{g} / \mathrm{ml})$} & \multicolumn{6}{|c|}{ Cytotoxicity } \\
\hline & TKA2 & TKA7 & TKA10 & TKA11 & TKA12 & Cisplatin \\
\hline 10 & 81.36 & 90.36 & 90.23 & 92.24 & 90.34 & 20.36 \\
\hline 20 & 78.36 & 81.57 & 85.96 & 86.22 & 81.23 & 39.64 \\
\hline 30 & 72.96 & 76.02 & 75.34 & 79.55 & 76.33 & 64.25 \\
\hline 40 & 66.78 & 63.25 & 64.36 & 70.22 & 68.23 & 75.88 \\
\hline 50 & 51.02 & 58.11 & 58.45 & 54.11 & 55.02 & 80.04 \\
\hline IC50 & 47.81 & 48.81 & 30.20 & 48.68 & 48.96 & 16.12 \\
\hline
\end{tabular}

\begin{tabular}{|c|c|c|c|c|c|c|}
\hline \multirow[t]{2}{*}{ Conc $(\mu \mathrm{g} / \mathrm{ml})$} & \multicolumn{6}{|c|}{ Cytotoxicity } \\
\hline & TKA2 & TKA7 & TKA10 & TKA11 & TKA12 & Cisplatin \\
\hline 10 & 72 & 71.36 & 70.98 & 73.96 & 69.33 & 20.36 \\
\hline 20 & 53.62 & 66.98 & 61.87 & 63.62 & 64.87 & 39.64 \\
\hline 30 & 78.5 & 61.33 & 55.62 & 61.23 & 59.25 & 64.25 \\
\hline 40 & 66.75 & 56.78 & 54.39 & 58.55 & 54.02 & 75.88 \\
\hline 50 & 43.2 & 54.98 & 51.69 & 54.61 & 51.44 & 80.04 \\
\hline $\mathrm{IC}_{50}$ & 48.81 & 48.59 & 39.34 & 48.31 & 40.97 & 16.12 \\
\hline
\end{tabular}

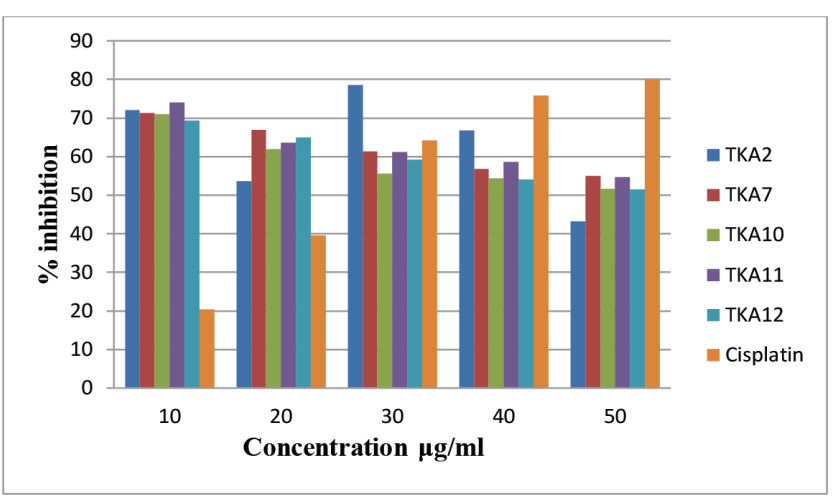

Figure 3: Cytotoxicity of the tested compounds on NCIH-460 assessed using MTT assay.

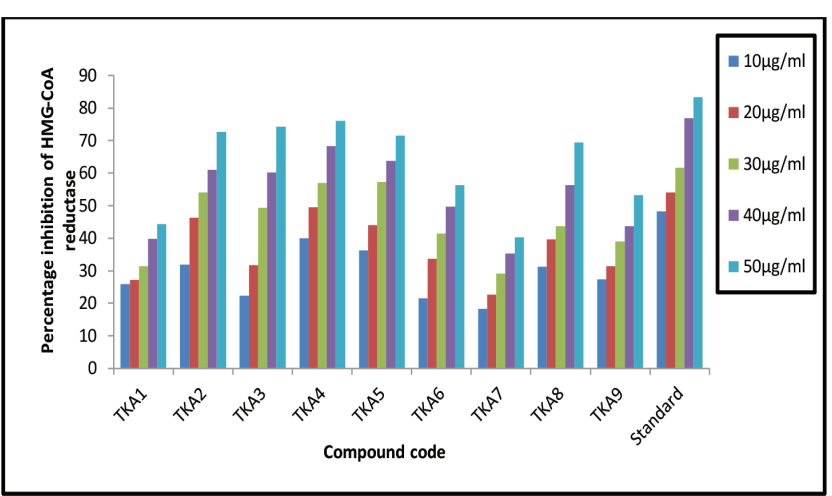

Figure 4: Inhibition activity of HMG-CoA reductase of coumarin coupled 4-thiazolidinone derivatives.

\begin{tabular}{|c|c|c|c|c|c|}
\hline \multirow[b]{2}{*}{ Compound code } & \multicolumn{5}{|c|}{ Percentage inhibition of HMG-CoA reductase } \\
\hline & $10 \mu \mathrm{g} / \mathrm{ml}$ & $20 \mu \mathrm{g} / \mathrm{ml}$ & $30 \mu \mathrm{g} / \mathrm{ml}$ & $40 \mu \mathrm{g} / \mathrm{ml}$ & $50 \mu \mathrm{g} / \mathrm{ml}$ \\
\hline TKA1 & 25.85 & 27.17 & 31.35 & 39.81 & 44.28 \\
\hline TKA2 & 31.92 & 46.28 & 54.11 & 61.03 & 72.61 \\
\hline TKA3 & 22.31 & 31.67 & 49.37 & 60.23 & 74.31 \\
\hline TKA4 & 40.02 & 49.51 & 56.91 & 68.26 & 76.02 \\
\hline TKA5 & 36.23 & 43.98 & 57.34 & 63.69 & 71.52 \\
\hline TKA6 & 21.54 & 33.71 & 41.38 & 49.73 & 56.39 \\
\hline TKA7 & 18.32 & 22.63 & 29.12 & 35.31 & 40.23 \\
\hline TKA8 & 31.23 & 39.63 & 43.63 & 56.32 & 69.36 \\
\hline TKA9 & 27.42 & 31.36 & 39.05 & 43.69 & 53.18 \\
\hline Standard & 48.16 & 54.06 & 61.58 & 76.84 & 83.34 \\
\hline
\end{tabular}


The compounds were tested in the concentration range of $10-50 \mu \mathrm{g} / \mathrm{ml}$. From the result it was found that antihyperlipidemic activity is concentration dependent. Some of the tested compounds TKA2, TKA3, TKA4, TKA5 showed potent antihyperlipidemic activity comparable with that of the standard pravastatin which may be due to the presence of electron withdrawing group like chloro and nitro. TKA6 and TKA 8 also showed good activity as given in Table 5 and Figure 4. So these compounds may be a promising antihyperlipidemic molecules which can be further determined by in vivo studies.

\section{CONCLUSION}

This study reports the successful synthesis of coumarinyl 4-thiazolidinone derivatives with moderate yields. Compound TKA12 showed potent cytotoxic activity on lung adenocarcinoma cells. Most of the synthesized compounds showed promising antihyperlipidemic activity. So these compounds may be a promising antihyperlipidemic molecules which can be further determined by in vivo studies.

\section{ACKNOWLEDGEMENT}

The authors are thankful to NITTE (Deemed to be University) for providing the necessary facilities to carry out this research.

\section{CONFLICT OF INTEREST}

The authors declare that there was no conflict of interest.

\section{ABBREVIATIONS}

HMG-CoA: $\quad \beta$-Hydroxy $\quad \beta$-methylglutaryl-CoA; OECD: Organisation for Economic Co-operation and Development; LDL: Low-density lipoproteins; NADPH: Nicotinamide adenine dinucleotide phosphate; IR: Infrared; ${ }^{1} \mathbf{H}$ NMR: Proton nuclear magnetic resonance; TLC: Thin layer chromatography; UV: Ultraviolet; ATR: Attenuated total reflection; ESI: Electrospray ionization; FBS: Fetal bovine serum; \%: Percentage; DMSO: Dimethyl sulfoxide; ${ }^{\circ} \mathbf{C}$ : Degree celsius; SD: Standard deviation; $\mu \mathrm{g} / \mathrm{ml}$ : Microgram/ millilitre; SD: standard deviation; mol: Mole; m.p:
Melting point; $\mathbf{R}_{\mathrm{f}}$ : Retardation factor; $\mu$ : Microliter; ml: Millilitre; nm: Nanometre; str: Stretching; MHz: Megahertz; $\mathbf{C D C l}_{3}$ : Deuterochloroform; d: Doublet; MS: Mass spectroscopy; J: Coupling constant; dd: Doublets of doublet; tt: Triplet of triplets; ddd: Doublet of doublets of doublets; dddd: Doublet of doublets of doublets of doublets.

\section{REFERENCES}

1. Lesyk R, Vladzimirska O, Holota S, Zaprutko L, Gzella A. New 5-substituted thiazolo [3,2-b] [1,2,4] triazol-6-ones: synthesis and anticancer evaluation. Eur J Med Chem. 2007;42(5):641-8. doi: 10.1016/j.ejmech.2006.12.006, PMID 17303290.

2. Santana L, Uriarte E, Dalla Via L, Gia O. A new benzoangelicin with strong photobiological activity. Bioorg Med Chem Lett. 2000;10(2):135-7. doi: 10.1016/s0960-894x(99)00640-x, PMID 10673096.

3. Guiotto A, Chilin A, Manzini P, Dall'Acqua F, Bordin F, Rodighiero P. Synthesis and antiproliferative activity of furocoumarin isosters. Farmaco. 1995;50(6):479-88. PMID 7669186.

4. Ploypradith P, Mahidol C, Sahakitpichan P, Wongbundit S, Ruchirawat S. A highly efficient synthesis of lamellarins $K$ and $L$ by the Michael addition/ringclosure reaction of benzyldihydroisoquinoline derivatives with ethoxycarbonylbeta-nitrostyrenes. Angew Chem Int Ed Engl. 2004;43(7):866-8. doi: 10.1002/ anie.200352043, PMID 14767960.

5. Hamdi N, Puerta MC, Valerga P. Synthesis, structure, antimicrobial and antioxidant investigations of dicoumarol and related compounds. Eur $\mathrm{J}$ Med Chem. 2008;43(11):2541-8. doi: 10.1016/j.ejmech.2008.03.038, PMID 18485537.

6. Voss ME, Carter PH, Tebben AJ, Scherle PA, Brown GD, Thompson LA, Xu M, Lo YC, Yang G, Liu RQ, Strzemienski P, Everlof JG, Trzaskos JM, Decicco CP. Both 5-arylidene-2-thioxodihydropyrimidine-4,6 $(1 \mathrm{H}, 5 \mathrm{H})$ diones and 3-thioxo-2,3-dihydro-1H-imidazo[1,5-a]indol-1-ones are lightdependent tumor necrosis factor-alpha antagonists. Bioorg Med Chem Lett. 2003;13(3):533-8. doi: 10.1016/s0960-894x(02)00941-1, PMID 12565966.

7. Jacob N, Kutty GN. Synthesis and hypolipidemic activity of a thiazolidinone derivative. Indian Drugs. 2004;41(2):76-9.

8. AK-Bayati IR, Kubba AAR, Radi MH. Synthesis of new pyrazole derivatives derived from 4-hydroxy coumarin and evaluation of their biological activity. A Mustan. J Sci. 2012;23(6):83-92.

9. Shirodkar SG, Girgaonkar MV. Synthesis, characterization and antimicrobial activity of some new Schiff bases derived from 3-acetyl-4-hydroxy-chromen2-one and primary aromatic amines. J Chem Pharm Res. 2012;4(05):260-4.

10. Samadhiya P, Sharma R, Srivastava SK, Srivastava SD. Synthesis and biological evaluation of 4-thiazolidinone derivatives as antitubercular and antimicrobial agents. Arab J Chem. 2014;7(5):657-65. doi: 10.1016/j. arabjc.2010.11.015.

11. Mosmann T. Rapid colorimetric assay for cellular growth and survival: application to proliferation and cytotoxicity assays. J Immunol Methods. 1983;65(1-2):55-63. doi: 10.1016/0022-1759(83)90303-4, PMID 6606682.

12. Jijith US, Jayakumari S. Screening methods for antihyperlipidemic activity: a review. Drug Invent Today. 2018;10(2):257-59.

13. Iqbal D, Khan MS, Khan A, Khan MS, Ahmad S, Srivastava AK et al. In vitro screening for -hydroxy--methylglutaryl-CoA reductase inhibitory and antioxidant activity of sequentially extracted fractions of Ficus palmata Forsk. BioMed Res Int. 2014:1-10. 
PICTORIAL ABSTRACT

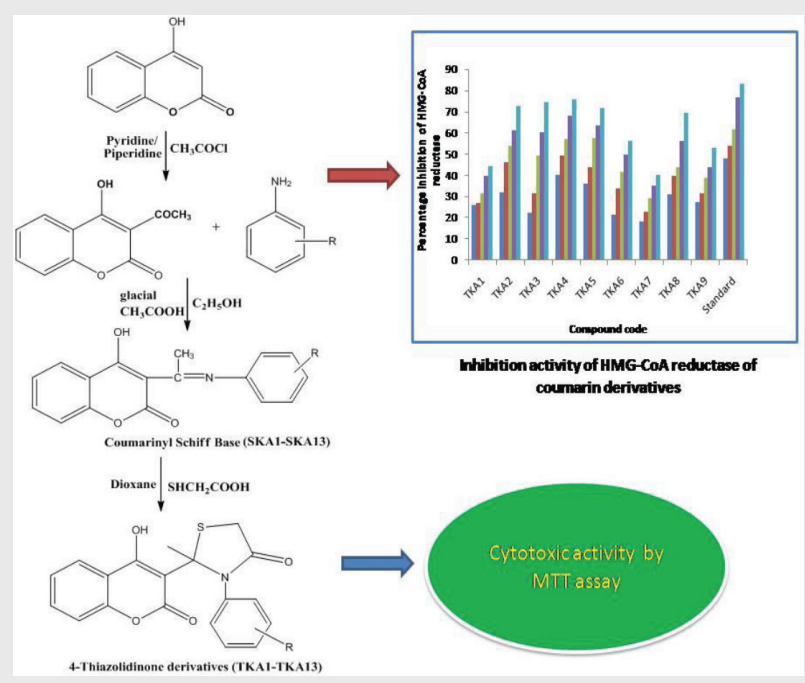

About Authors

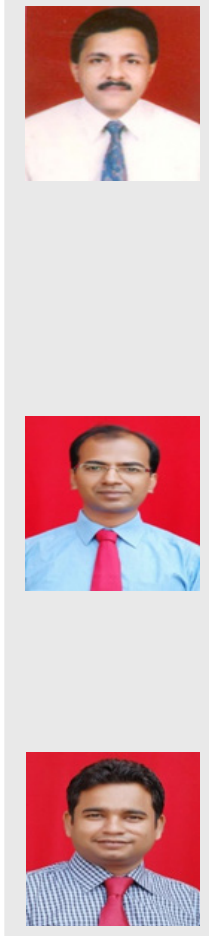

Dr. K Ishwar Bhat, Professor, Department of Pharmaceutical Chemistry at NGSM Institute of Pharmaceutical Sciences, Nitte (Deemed to be University) Mangaluru, Karnataka. He has more than 35 years of teaching and research experience, his area of interest is synthetic organic chemistry. He has published 110 research articles in various national and international journals, and applied for 2 Indian patents.

Dr. Abhishek Kumar is working as Assistant Professor, Department of Pharmaceutical Chemistry at NGSM Institute of Pharmaceutical Sciences, Mangaluru. His areas of interest are synthetic organic chemistry, insilico studies and spectral analysis of synthesized organic compounds.

Dr. Pankaj Kumar is currently working as Assistant Professor in the Department of Pharmaceutical Chemistry at NGSM Institute of Pharmaceutical Sciences, Mangalore, Karnataka. He has more than 10 years of experience in teaching and research. His area of interest is computational chemistry and synthetic chemistry.

\section{SUMMARY}

- Cancer still remains an unconquered problem, despite tremendous advancements both in early diagnosis and approaches to treatment. The development of new chemotherapeutic agents for the treatment of cancer with fewer side effects is an important goal for medicinal chemists. Hyperlipidemia is a worth-mentioning risk factor in quickly expanding cardiovascular diseases, including myocardial infarction and, furthermore, in stroke.

- This inculcated the need for synthesizing new coumarin incorporated 4-thiazolidinone derivatives and to probe how this combination could influence the cytotoxic and antihyperlipidemic activity.

- In the present study, a series of new substituted 2-(4-hydroxy-2-oxo-2H-chromen-3-yl)-2-methyl3-phenylthiazolidin-4-one (TKA1-TKA13) were synthesized by reacting various 4-hydroxy-3-(1(phenylimino)ethyl)-2H-chromen-2-one with thioglycollic acid. The intermediate 4-hydroxy3-(1-(phenylimino)ethyl)-2H-chromen-2-one (SKA1-SKA13) were synthesized by reacting 4-hydroxyl coumarin with various substituted anilines in alcohol medium.

- The newly synthesized compounds were evaluated for in-vitro cytotoxic activity using Methyl Thiazolyl Tetrazolium (MTT) assay and in-vitro antihyperlipidemic activity by HMG-CoA reductase assay.

- Compound TKA12 possess potent cytotoxic activity on lung adenocarcinoma cells in a concentration dependent manner compared to the standard cisplatin. Most of the compounds showed potent antihyperlipidemic activity comparable with that of the standard pravastatin.

Cite this article: Bhat KI, Kumar A, Kumar P. Synthesis, Cytotoxic and Antihyperlipidemic Activities of Some New coumarinyl 4-Thiazolidinone Derivatives. Indian $\mathrm{J}$ of Pharmaceutical Education and Research. $2021 ; 55(3 \mathrm{~s}):$ s807-s813. 